(2) Open Access Full Text Article

REVIEW

\title{
Patient considerations in the use of transdermal iontophoretic fentanyl for acute postoperative pain
}

\author{
This article was published in the following Dove Press journal: \\ Journal of Pain Research \\ 19 April 2016 \\ Number of times this article has been viewed
}

\author{
Craig T Hartrick' \\ Cecile R Pestano' \\ Li Ding ${ }^{2}$ \\ Hassan Danesi ${ }^{2}$ \\ James B Jones ${ }^{2}$ \\ 'Beaumont Health System, Troy, MI, \\ ${ }^{2}$ The Medicines Company, Parsippany, \\ NJ, USA
}

\begin{abstract}
Opioids are commonly used in the management of moderate-to-severe postoperative pain. Patient-controlled analgesic techniques are recognized as preferred administration methods. Previously, research has focused on intravenously administered opioids via a programmable pump. More recently, an iontophoretic transdermal system (ITS), which is patient controlled, has been developed. The focus of this review is on pain management using the fentanyl ITS during the 24-72-hour time period immediately following surgery. Fentanyl ITS offers a needle-free alternative to traditional intravenous (IV) patient-controlled analgesia (PCA) system that is as effective and safe as IV PCA. This system is easy to use for both patients and nurses. The use of fentanyl ITS is generally associated with a better ease-of-care profile, including a greater ease of mobility, from a patients' perspective when compared with morphine IV PCA.

Keywords: patient-controlled analgesia, fentanyl iontophoretic transdermal system, ease of care, mobility, patient perspective, review
\end{abstract}

\section{Introduction to opioid analgesia in acute postoperative pain}

Pain management for surgical patients occurs before, during, and after procedures with the goal of reducing or eliminating postoperative pain. ${ }^{1}$ Opioids are frequently utilized in the management of acute moderate-to-severe postoperative pain immediately after surgery as part of an analgesic multimodal therapy regimen. ${ }^{1,2}$ In a retrospective review, as many as $98.6 \%$ of postoperative patients received an opioid medication during this time period. ${ }^{3}$ Patient-controlled analgesia (PCA) is commonly used to administer opioids in the postoperative period for pain management. Intravenous (IV) PCA is associated with a higher level of patient satisfaction and slightly better pain control than nonpatient-controlled methods. ${ }^{4}$ Although more recently there has been more attention on other modalities such as an iontophoretic transdermal system (ITS) that are patient controlled and easier for both patients and nurses to utilize, ${ }^{5-8}$ most research has focused on intravenously administered opioids via a programmable pump. ${ }^{4}$ The focus of this review is on pain management during the 24-72-hour time period immediately following a surgical procedure.

\section{Fentanyl ITS}

The fentanyl ITS (IONSYS ${ }^{\circledR}$; The Medicines Company, Parsippany, NJ, USA) is a PCA system that is indicated for the short-term management of acute postoperative pain in adult patients requiring opioid analgesia in the hospital. ${ }^{9}$ Fentanyl ITS utilizes
Correspondence: Craig T Hartric

Dequindre Road, Troy, MI 48085, USA

Email chartrick@beaumont.edu 
iontophoresis, which provides a needle-free, noninvasive delivery of fentanyl via intact skin. The active ingredient in fentanyl ITS is fentanyl (10.8 $\mathrm{mg}$ fentanyl hydrochloride is equivalent to $9.7 \mathrm{mg}$ fentanyl).

\section{lontophoresis}

Iontophoresis is a technique that permits the dosing of medicinal compounds through the skin by applying an imperceptible local electric current. Iontophoresis allows for rapid transdermal delivery of a drug (such as fentanyl) across intact skin, which is ideally suited to acute pain management. The fentanyl ITS system consists of a bottom housing unit called the drug unit and a top housing unit called controller (Figure 1A). The drug unit contains anode and cathode electrodes and hydrogels that convert the dose current from the controller into the flux of fentanyl ions through the skin. A small ionic current of $170 \mu \mathrm{A}$ is applied when the system is activated by the patient, which results in the active delivery of fentanyl ions across the skin and into systemic circulation. The amount of fentanyl delivered across the surface of the skin is directly related to the amount of current applied..$^{10,11}$ In a pharmacokinetic study, it was determined that a current of $170 \mu \mathrm{A}$ resulted in the absorption of $39.5 \mu \mathrm{g}$ of fentanyl at hour $23 .{ }^{10}$ Prior to this pharmacokinetic study, Camu et al had determined that the $40 \mu \mathrm{g}$ dose was an effective therapeutic dose for fentanyl. ${ }^{12}$ Therefore, clinical trials utilized the $170 \mu \mathrm{A}$ system. A full description of the design has been published by Joshi et al. ${ }^{13}$

\section{System design}

Fentanyl ITS consists of a drug unit and a controller. The drug unit contains the fentanyl, and the controller is the medical device that controls the operation of the system. The anode and cathode electrodes and hydrogels that convert the electrical current from the controller are present in the drug unit. ${ }^{13}$ The bottom drug unit and the top controller unit are snapped together by the nurse immediately prior to the application of the system to the patient's chest or upper outer arm (Figure 1A-C). The digital display of the controller completes a short self-test during which there is one audible beep; the red light then blinks once and the digital display flashes the number " 88 " upon assembly. Once the self-test is completed, the digital display shows the number " 0 " and the green light blinks at a slow rate to indicate that it is ready for use. Dose administration is started by the patient pressing and releasing a recessed button on the top of the system twice within 3 seconds (Figure 1C). When dose administration occurs (when the system is activated by the patient and a small ionic current of $170 \mu \mathrm{A}$ is applied,
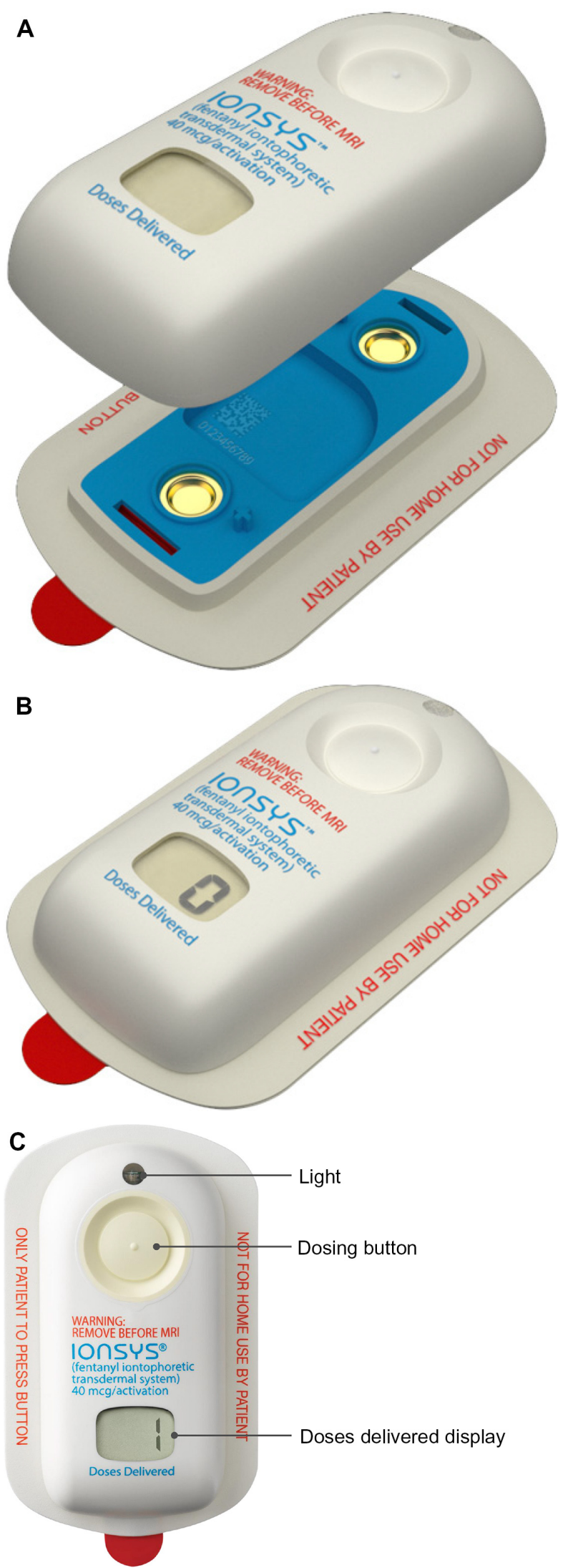

Figure I An illustration of the fentanyl ITS controller and drug unit.

Notes: (A) Controller and drug unit prior to assembly. (B) Assembled fentanyl ITS system. (C) Fentanyl ITS user interface. Used with permission of The Medicines Company (Parsippany, NJ, USA).

Abbreviation: ITS, iontophoretic transdermal system. 
resulting in the delivery of fentanyl ions across the skin and into systemic circulation), the light changes from a slow blinking green to a fast blinking green and a single audible beep is emitted. The dose is administered over a 10-minute period. During the 10 minutes, the light blinks green at a fast rate and the display alternates between a walking circle and the number of doses delivered. Once 10 minutes has passed, the green light will return to a slow rate of blinking and the patient can now administer another dose. The number of doses administered appears in the digital dosing display. A maximum of six $40 \mu \mathrm{g}$ doses can be administered per hour with each system operating for up to 24 hours or until 80 doses have been administered whichever occurs first, upon which the system becomes inoperable.

When assembled, the system confirms that the hardware conditions (correct battery and reference voltages and timer signal) necessary for the integrated circuit to operate properly are present before booting up the software. If any of these conditions are not met, the system will remain off. Additional self-tests are run periodically throughout the life cycle of the assembled system. In the event that any of the self-tests fail or a potentially unsafe condition is detected such as poor skin contact, low battery, defective system, and system error, the controller delivers audible beeps to alert the nurse or other health care workers to check the system and troubleshoot as necessary or the software shuts down the system safely and permanently.

The fentanyl ITS system is approved by the US Food and Drug Administration for use in the hospital for 24-72 hours. The system must be discontinued prior to hospital discharge (ie, removed from the patient) and properly disposed of according to the institution's procedures for handling narcotics.

\section{Mode of action}

Fentanyl is an opioid analgesic that was originally synthesized by Paul Janssen (Janssen Pharmaceutica, Beerse, Belgium) in $1959 .{ }^{14}$ Fentanyl interacts predominantly with the opioid $\mu$-receptor and exerts its analgesic effect by mimicking the effects of endogenous opioid peptides (eg, endorphins). ${ }^{15,16}$ Fentanyl is $\sim 50-100$ times more potent than morphine. ${ }^{15}$ Like with other opioids, overdose is reversible with naloxone treatment.

\section{Efficacy}

There have been three Phase III randomized, double-blind, clinical trials and four Phase IIIB randomized, open-label, active-comparator clinical trials conducted that utilized fentanyl ITS in the management of postoperative pain (Table 1). Two of the Phase III trials and all four Phase IIIB trials have been previously reported..$^{5-8,17,18}$ All patients were approached about the study prior to their surgical procedure and screened within 2 weeks of enrollment. The eligible patients were at least 18 years of age. Patients had to be awake, alert, and breathing spontaneously for at least 30 minutes. For the majority of the studies, patients were titrated to an acceptable level of comfort using IV bolus doses of opioids. There were a variety of patient groups included in the seven trials (ie, surgeries included abdominal, pelvic, orthopedic, and thoracic). In the three double-blind trials, fentanyl ITS was superior to placebo on the primary outcome measure of patients discontinuing the study due to inadequate analgesia (Table 1). In the four open-label, active-comparator trials, fentanyl ITS demonstrated equal efficacy to morphine IV PCA on the primary outcome measure of the Patient's Global Assessment (PGA) of their pain control method (Table 1). All seven trials included both the PGA of the method of pain control at 24 hours and the Investigator's Global Assessment (IGA) of the method of pain control at the last assessment. The PGA is a validated scale that uses a single patientreported outcome ("Overall, would you rate this method of pain control during the past 24 hours as being poor, fair, good or excellent?"). ${ }^{19}$ Success on the PGA is defined as a rating of either excellent or good. In the three double-blind trials, fentanyl ITS was superior to placebo on this outcome, and in the four open-label trials, fentanyl ITS demonstrated similar results to morphine IV PCA (Figure 2). The IGA uses a single investigator-reported outcome ("Overall, would you rate this method of pain control for this patient during the last 24 hours as being poor, fair, good, or excellent?"). Success on the IGA is defined as a rating of either excellent or good. In the three double-blind trials, fentanyl ITS was superior to placebo on this outcome (ie, success on the IGA), and in the four open-label trials, fentanyl ITS demonstrated similar results to morphine IV PCA (ie, success on the IGA; Figure 3). A meta-analysis has been conducted utilizing the data from the four Phase IIIB active-comparator trials. ${ }^{20}$ In this meta-analysis, fentanyl ITS was superior to morphine IV PCA in terms of both the PGA rating of "excellent" (fentanyl ITS $=45.2 \%$ vs morphine IV PCA $=35.0 \%$ of patients reporting ratings of "excellent"; odds ratio $=1.53$, $P<0.0001$ ) and the IGA rating of "excellent" (fentanyl ITS $=59.1 \%$ vs morphine IV PCA $=38.3 \%$ of investigators reporting ratings of "excellent"; odds ratio $=2.58, P<0.0001$ ).

\section{Safety and tolerability}

Fentanyl has been utilized for $>45$ years. The overall safety profile for fentanyl is similar to other opioid agents. Specifically, the safety and tolerability of 
Table I Overview of Phases III and IIIB clinical trials with fentanyl ITS

\begin{tabular}{|c|c|c|c|c|c|c|}
\hline & Site information & $\begin{array}{l}\text { Type of surgical } \\
\text { procedures }\end{array}$ & $\begin{array}{l}\text { Fentanyl } \\
\text { dosing (n) }\end{array}$ & $\begin{array}{l}\text { Comparator } \\
\text { dosing (n) }\end{array}$ & $\begin{array}{l}\text { Primary efficacy } \\
\text { assessment }\end{array}$ & Outcome \\
\hline \multicolumn{7}{|c|}{ Randomized, double-blind, placebo-controlled trials (duration of studies: up to 24 hours; Phase III) } \\
\hline C-95-016 & $\begin{array}{l}\text { Single site, } \\
\text { New Zealand }\end{array}$ & $\begin{array}{l}\text { Abdominal } \\
\text { Orthopedic }\end{array}$ & $\begin{array}{l}\text { Fentanyl ITS } \\
40 \mu g \text { up to } \\
6 \text { doses } / \mathrm{h} \\
(\mathrm{n}=77)\end{array}$ & $\begin{array}{l}\text { Placebo ITS } \\
(n=25)\end{array}$ & $\begin{array}{l}\text { Number of patients } \\
\text { who withdrew due to } \\
\text { inadequate pain control } \\
\geq 3 \text { hours after application } \\
\text { of study treatment }\end{array}$ & $\begin{array}{l}\text { Fentanyl ITS } \\
\text { superior to } \\
\text { placebo ITS }\end{array}$ \\
\hline Chelly et al ${ }^{17}$ & 10 sites, USA & $\begin{array}{l}\text { Abdominal } \\
\text { Orthopedic } \\
\text { Thoracic }\end{array}$ & $\begin{array}{l}\text { Fentanyl ITS } \\
40 \mu g \text { up to } \\
6 \text { doses } / \mathrm{h} \\
(\mathrm{n}=154)\end{array}$ & $\begin{array}{l}\text { Placebo ITS } \\
(n=5 I)\end{array}$ & $\begin{array}{l}\text { Percentage of patients } \\
\text { who withdrew due to } \\
\text { inadequate pain control } \\
\geq 3 \text { hours after application } \\
\text { of study treatment }\end{array}$ & $\begin{array}{l}\text { Fentanyl ITS } \\
\text { superior to } \\
\text { placebo ITS }\end{array}$ \\
\hline Viscusi et al ${ }^{18}$ & 20 sites, USA & $\begin{array}{l}\text { Abdominal } \\
\text { Orthopedic } \\
\text { Thoracic } \\
\text { Others }\end{array}$ & $\begin{array}{l}\text { Fentanyl ITS } \\
40 \mu g \text { up to } \\
6 \text { doses } / \mathrm{h} \\
(\mathrm{n}=244)\end{array}$ & $\begin{array}{l}\text { Placebo ITS } \\
(\mathrm{n}=240)\end{array}$ & $\begin{array}{l}\text { Percentage of patients } \\
\text { who withdrew due to } \\
\text { inadequate pain control } \\
\geq 3 \text { hours after application } \\
\text { of study treatment }\end{array}$ & $\begin{array}{l}\text { Fentanyl ITS } \\
\text { superior to } \\
\text { placebo ITS }\end{array}$ \\
\hline \multicolumn{7}{|c|}{ Randomized, open-label, active-comparator trials (duration of studies: up to 72 hours; Phase IIIB) } \\
\hline Viscusi et $\mathrm{al}^{8}$ & $\begin{array}{l}33 \text { sites, USA } \\
\text { and Canada }\end{array}$ & $\begin{array}{l}\text { Abdominal } \\
\text { Orthopedic } \\
\text { Thoracic } \\
\text { Others }\end{array}$ & $\begin{array}{l}\text { Fentanyl ITS } \\
40 \mu g \text { up to } \\
6 \text { doses } / \mathrm{h} \\
(\mathrm{n}=316)\end{array}$ & $\begin{array}{l}\text { Morphine IV PCA } \\
(1 \mathrm{mg} / \text { dose }) \text { up to } \\
10 \text { doses/h } \\
(\mathrm{n}=320)\end{array}$ & $\begin{array}{l}\text { PGA ratings of either } \\
\text { "excellent" or "good" } \\
\text { in the first } 24 \text { hours }\end{array}$ & $\begin{array}{l}\text { Fentanyl ITS } \\
\text { equivalent } \\
\text { to } \\
\text { morphine IV } \\
\text { PCA }\end{array}$ \\
\hline Hartrick et al ${ }^{6}$ & 52 sites, USA & Orthopedic & $\begin{array}{l}\text { Fentanyl ITS } \\
40 \mu g \text { up to } \\
6 \text { doses } / \mathrm{h} \\
(\mathrm{n}=395)\end{array}$ & $\begin{array}{l}\text { Morphine IV PCA } \\
(I \mathrm{mg} / \text { dose }) \text { up to } \\
10 \text { doses } / \mathrm{h} \\
(\mathrm{n}=404)\end{array}$ & $\begin{array}{l}\text { PGA ratings of either } \\
\text { "excellent" or "good" } \\
\text { in the first } 24 \text { hours }\end{array}$ & $\begin{array}{l}\text { Fentanyl ITS } \\
\text { equivalent } \\
\text { to } \\
\text { morphine IV } \\
\text { PCA }\end{array}$ \\
\hline Minkowitz et al ${ }^{7}$ & 39 sites, USA & $\begin{array}{l}\text { Abdominal } \\
\text { Pelvic }\end{array}$ & $\begin{array}{l}\text { Fentanyl ITS } \\
40 \mu g \text { up to } \\
6 \text { doses } / \mathrm{h} \\
(\mathrm{n}=252)\end{array}$ & $\begin{array}{l}\text { Morphine IV PCA } \\
(1 \mathrm{mg} / \text { dose }) \text { up to } \\
10 \text { doses } / \mathrm{h} \\
(\mathrm{n}=254)\end{array}$ & $\begin{array}{l}\text { PGA ratings of either } \\
\text { "excellent" or "good" } \\
\text { in the first } 24 \text { hours }\end{array}$ & $\begin{array}{l}\text { Fentanyl ITS } \\
\text { equivalent } \\
\text { to } \\
\text { morphine IV } \\
\text { PCA }\end{array}$ \\
\hline Grond et al ${ }^{5}$ & $\begin{array}{l}51 \text { sites in } \\
\text { II European } \\
\text { countries }\end{array}$ & $\begin{array}{l}\text { Abdominal } \\
\text { Orthopedic }\end{array}$ & $\begin{array}{l}\text { Fentanyl ITS } \\
40 \mu g \text { up to } \\
6 \text { doses } / \mathrm{h} \\
(\mathrm{n}=325)\end{array}$ & $\begin{array}{l}\text { Morphine IV PCA } \\
(1 \mathrm{mg} / \text { dose }) \text { up to } \\
10 \text { doses } / \mathrm{h} \\
(\mathrm{n}=335)\end{array}$ & $\begin{array}{l}\text { PGA ratings of either } \\
\text { "excellent" or "good" in the } \\
\text { first } 24 \text { hours }\end{array}$ & $\begin{array}{l}\text { Fentanyl ITS } \\
\text { equivalent } \\
\text { to } \\
\text { morphine IV } \\
\text { PCA }\end{array}$ \\
\hline
\end{tabular}

Note: a Data from The Medicines Company, unpublished data, 2016.

Abbreviations: ITS, iontophoretic transdermal system; IV PCA, intravenous patient-controlled analgesia; PGA, patient global assessment.

fentanyl ITS has been studied in greater than 2,000 patients with acute postoperative pain in controlled and uncontrolled trials. The adverse event profile seen in the clinical studies is consistent with expected adverse events with fentanyl treatment. The most frequently reported adverse events with fentanyl ITS compared to placebo in the double-blind trials were nausea (39\% vs $22 \%$ ), application site erythema ( $14 \%$ vs $2 \%)$, vomiting ( $12 \%$ vs $6 \%$ ), headache ( $9 \%$ vs $7 \%)$, and pruritus $(6 \%$ vs $<1 \%){ }^{9}$ In the four Phase IIIB active-comparator trials, the most frequently reported adverse events that occurred with fentanyl ITS compared with morphine IV PCA were nausea $(40.3 \%$ vs $44.5 \%)$, pyrexia ( $18.4 \%$ vs $16.9 \%)$, vomiting $(13.0 \%$ vs
$12.4 \%)$, application site erythema ( $14.0 \%$ vs $0 \%)$, headache $(9.3 \%$ vs $5.9 \%)$, pruritus $(5.5 \%$ vs $9.4 \%)$, and anemia $(6.0 \%$ vs $6.6 \%) .{ }^{21}$ In the studies, clinically relevant respiratory depression (CRRD) was defined as the simultaneous occurrence of bradypnea (respiratory rate $<8$ breaths/min sustained for 1 minute) and excessive sedation (patient not easily aroused). Also included in the evaluation were assessments of upper airway obstruction, vital signs, oxygen saturation, and the need for clinical intervention. Importantly, no patients treated with fentanyl ITS during the clinical development of the system experienced CRRD, whereas there were five patients treated with morphine IV PCA who experienced CRRD. 


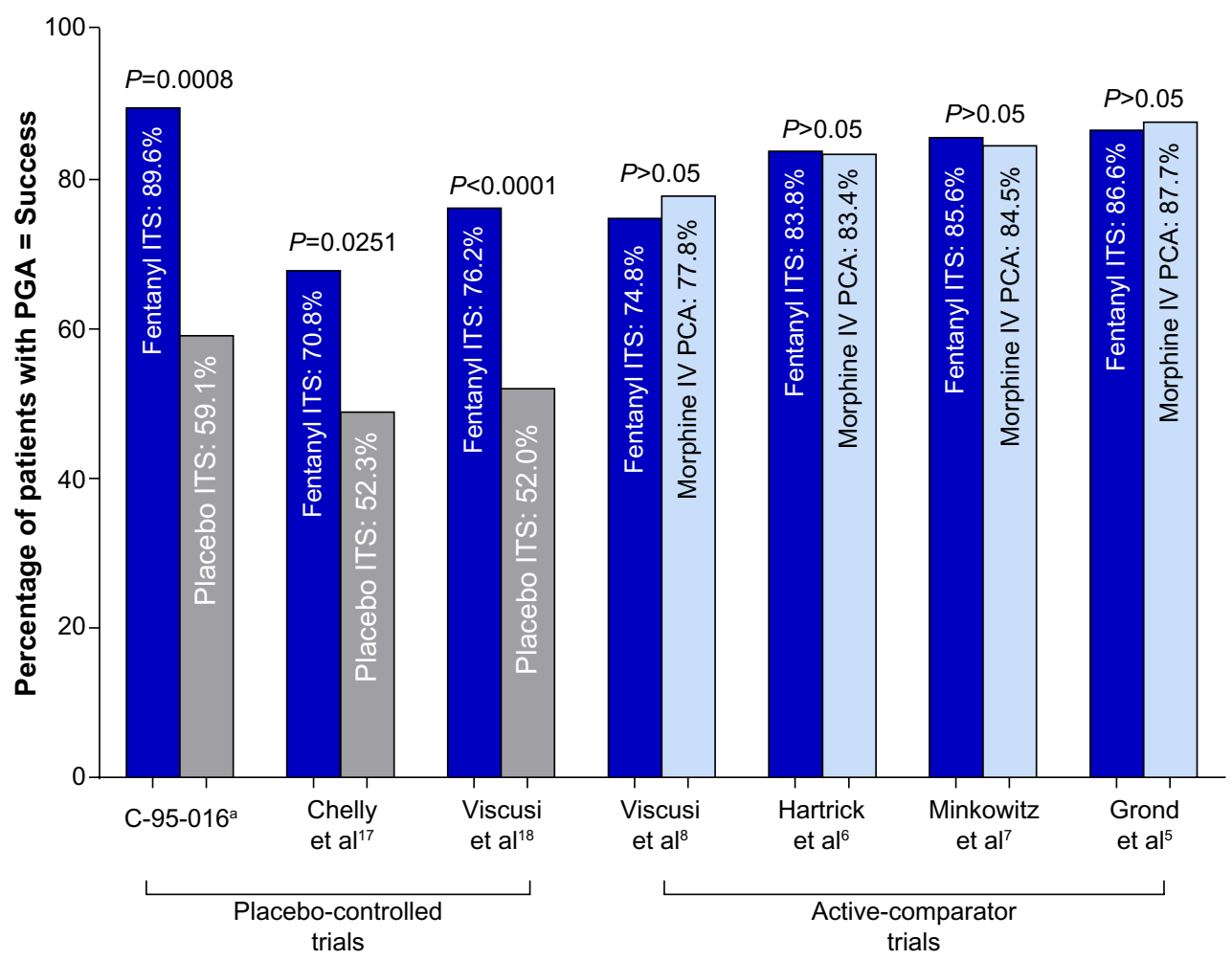

Figure 2 PGA rating of success at 24 hours.

Notes: a Data from The Medicines Company, unpublished data, 2016. Data represent a post hoc analysis of patients with baseline pain scores $<75$ on a visual analog scale at study entry.

Abbreviations: ITS, iontophoretic transdermal system; IV PCA, intravenous patient-controlled analgesia; PGA, patient global assessment.

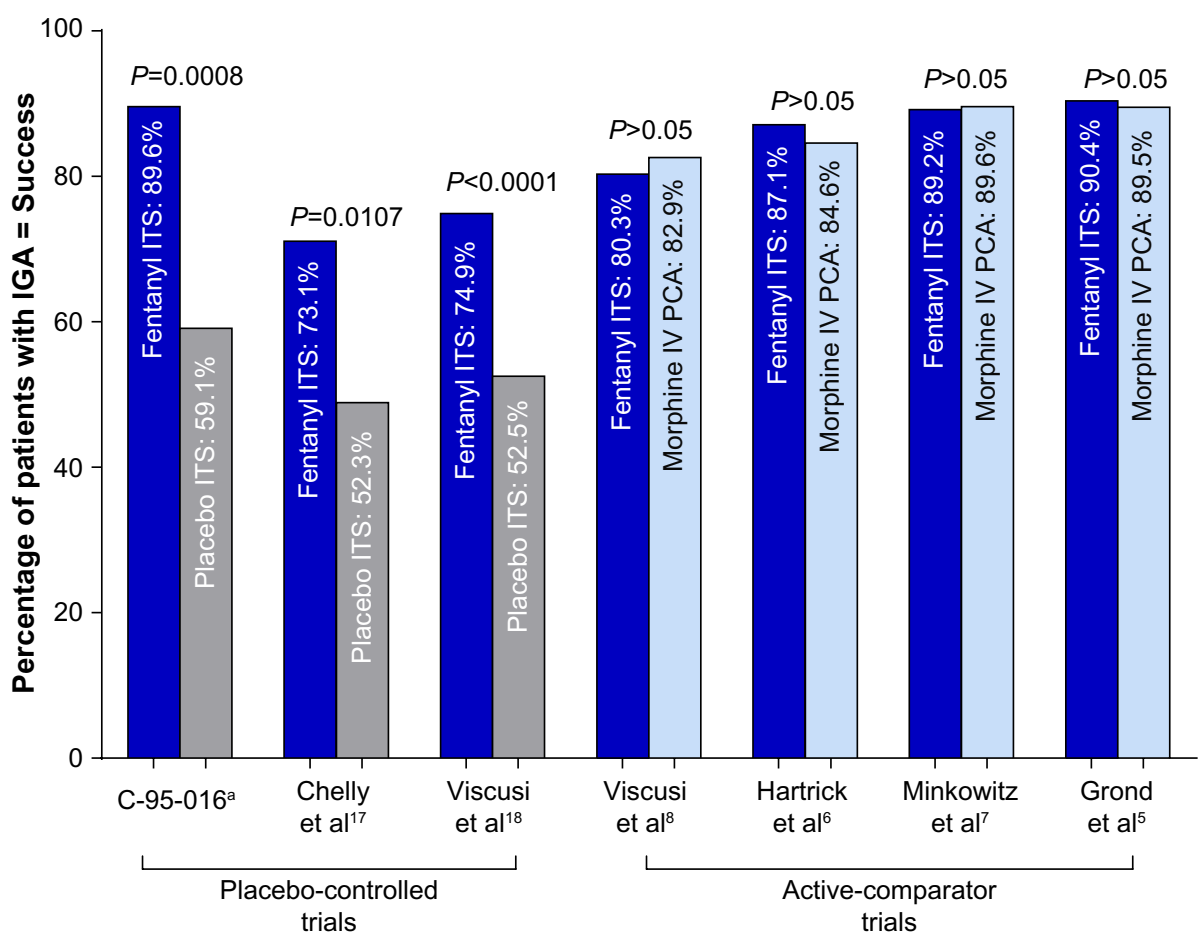

Figure 3 IGA rating of success at the last assessment.

Notes: ${ }^{\mathrm{D}}$ Data from The Medicines Company, unpublished data, 2016. Data represent a post hoc analysis of patients with baseline pain scores $<75$ on a visual analog scale at study entry.

Abbreviations: IGA, Investigator's Global Assessment; ITS, iontophoretic transdermal system; IV PCA, intravenous patient-controlled analgesia. 


\section{Patient considerations}

Studies have shown that patients prefer PCA to conventional techniques of analgesia. ${ }^{4}$ PCA has become the standard care in many hospitals for the management of postoperative and other pain requiring opioid analgesia. In addition, individual responses to pain also vary widely, so self-titration to the dose that controls pain is an attractive proposition.

During the clinical development program, it was very important to evaluate how patients would be able to learn and use the fentanyl ITS system effectively. This was accomplished through a series of "human factors" studies that were designed to specifically gauge if and how real-world patients and simulated patients (ie, healthy volunteers) would be able to utilize the fentanyl ITS system. ${ }^{22}$ During this process, minimal changes were made to the system to increase usability and clarifications were made to the instructions for use and disposal. Patient users (or healthy volunteers) were able to effectively utilize the system with no close calls, which would result in potential harm to themselves. The final study conducted was to evaluate the training that patients would receive prior to starting fentanyl ITS. After receiving formal training from their nurse, all patients were able to effectively utilize the system. Overall, in the human factors studies, patients and simulated patients found fentanyl ITS very easy to use.

Ease of care (EOC) in patients was formally tested during the development of fentanyl ITS using the validated patient EOC questionnaire. ${ }^{23,24}$ The patient EOC questionnaire consists of 23 items that are grouped into seven subscales (confidence with device, comfort with device, movement, dosing confidence, pain control, knowledge/understanding, and satisfaction). Data from two Phase IIIB studies (Hartrick et al, total hip arthroplasty [THA $]^{6}$ and Minkowitz et al, abdominal or pelvic surgery $[\mathrm{APS}]^{7}$ ) were pooled in an analysis that utilized the patient EOC questionnaire. ${ }^{23}$ The EOC questionnaire was completed by the patient at 72 hours or at study discontinuation. The majority of EOC items showed greater percentages of patients who reported the most positive response for fentanyl ITS than they did for morphine IV PCA in both studies. However, the value patients placed on the particular pain management technique varied with the pain model.

In the THA study, ${ }^{6}$ there were no differences between fentanyl ITS and morphine IV PCA in either comfort with the device or dosing confidence. Statistically significant differences were found favoring fentanyl ITS over morphine IV PCA in, confidence with the device $(91.5 \%$ vs $81.3 \%$; $P<0.001$ ), pain control (76.8\% vs $69.9 \% ; P=0.034)$, knowledge and understanding $(72.8 \%$ vs $64.4 \% ; P=0.013)$, and satisfaction $(75.7 \%$ vs $66.7 \% ; P<0.001)$ subscales. Despite numeric superiority of each of these subscales favoring fentanyl ITS in the APS study, ${ }^{7}$ they did not reach statistical significance, highlighting the differing patient needs under differing postoperative pain conditions.

Mobility is a key factor to patient recovery. Mobility is both important in reducing morbidity such as pneumonia and pulmonary embolus and decreasing hospital length of stay. ${ }^{25,26}$ While early mobility is critical to minimizing these and other postoperative complications following both major orthopedic surgery (THA) and surgery involving abdominal incision (APS), specific movement challenges patients are presented with differ. However, irrespective of pain model, fentanyl ITS offers a significant advantage over IV PCA because it does not require the patient to be attached to a pump. Therefore, if there is no other need for intravenous access, the patient may have improved mobility and ambulation, which could lead to reduced morbidity.

Movement, as assessed on the EOC questionnaire, included questions reflecting the ability to provide self-care (ability to eat, brush teeth, sit up in bed; question 11), adjusting position in bed (question 12), and getting out of bed (to sit in a chair and walk to bathroom and down the hallway; question 13). Taken together, significant improvements in overall mobility were reported in both the THA study ${ }^{6}$ and the APS study. ${ }^{7}$ Subsequent detailed analyses of the THA study ${ }^{6}$ and the APS study, ${ }^{7}$ studies ${ }^{19}$ reported percentages of patients attributing the most positive favorable responses contributing to overall EOC with respect to movement. THA patients reported the most positive contributions for self-care ( $87.8 \%$ vs $48.8 \%$ ), adjusting position in bed ( $92.4 \%$ vs $57.2 \%$ ), and getting out of bed $(94.7 \%$ vs $42.6 \%$ ), each favoring fentanyl ITS over morphine IV PCA, respectively. Similar results were reported in APS patients for self-care (88.5\% vs $45.7 \%$ ), adjusting position in bed (93.3\% vs $57.1 \%$ ), and getting out of bed ( $95.6 \%$ vs $49.2 \%$ ), favoring fentanyl ITS over morphine IV PCA, respectively.

The fentanyl ITS system has been found to improve mobility as assessed not only by patients ${ }^{23,27}$ but also through separate validated EOC questionnaires designed for nurses ${ }^{27}$ and for physical therapists. ${ }^{28}$ Patients may benefit from nursing improved EOC by allowing the nurses to have additional time to devote to direct patient care instead of dealing with issues related to the pain management device itself. Likewise, facilitation of physical therapists' functioning may translate into an improved rehabilitation experience.

Fentanyl ITS is intended only for use in a hospital setting. Before starting fentanyl ITS, patients should be titrated to an acceptable level of analgesia using alternative routes of administration postsurgically. It may be used only in adult patients for the short-term management of acute postoperative pain. As with IV PCA treatment, only patients 
who are alert enough and have adequate cognitive ability are suitable candidates. One limitation of the system is that it delivers a fixed dose (ie, $40 \mu \mathrm{g} / \mathrm{dose}$ ) and does not allow any dose adjustment; consequently, it is not intended for opioid-tolerant patients.

\section{Hospital and patient training}

Fentanyl ITS is indicated for use only in a hospital and is removed by the health care professional before the patient leaves the hospital. Prior to receiving and using fentanyl ITS, hospitals have to be certified per a product-specific Risk Evaluation and Mitigation Strategy program. The Risk Evaluation and Mitigation Strategy program ensures that staff will be trained on proper use before using the product. Patient training has been formalized and tested in human factors trials and has been found to be sufficient. All patients must undergo standardized training prior to fentanyl ITS initiation.

\section{Conclusion}

With fentanyl ITS, fentanyl is delivered into the systemic circulation of patients using iontophoresis. The system has been designed to be easily utilized by patients and is easy to apply by nurses. In clinical trials, fentanyl ITS was found to be superior to placebo and as effective as morphine IV PCA in patients with moderate-to-severe postoperative pain. Overall, the use of fentanyl ITS is generally associated with a better EOC profile, including a greater ease of mobility, from a patients' perspective when compared with morphine IV PCA. Fentanyl ITS offers a needle-free alternative to traditional IV PCA system that is as effective and safe as IV PCA.

\section{Acknowledgments}

The writing of this manuscript was supported financially by The Medicines Company. The authors thank Starr Grundy, BSc (Pharm), of SD Scientific, Inc., for medical writing support for this manuscript.

\section{Disclosure}

Craig Hartrick and Cecile Pestano are on the speakers bureau for The Medicines Company. Li Ding and Hassan Danesi are employees of The Medicines Company and James B Jones is a former employee of The Medicines Company. The authors report no other conflicts of interest in this work.

\section{References}

1. American Society of Anesthesiologists Task Force on Acute Pain Management. Practice guidelines for acute pain management in the perioperative setting: an updated report by the American Society of Anesthesiologists Task Force on Acute Pain Management. Anesthesiology. 2012;116(2):248-273.
2. Strassels SA, McNicol E, Suleman R. Postoperative pain management: a practical review, part 1. Am J Health Syst Pharm. 2005;62(18): 1904-1916.

3. Kessler ER, Shah M, Gruschkus SK, Raju A. Cost and quality implications of opioid-based postsurgical pain control using administrative claims data from a large health system: opioid-related adverse events and their impact on clinical and economic outcomes. Pharmacotherapy. 2013;33(4):383-391.

4. McNicol ED, Ferguson MC, Hudcova J. Patient controlled opioid analgesia versus non-patient controlled opioid analgesia for postoperative pain. Cochrane Database Syst Rev. 2015;6: CD003348.

5. Grond S, Hall J, Spacek A, Hoppenbrouwers M, Richarz U, Bonnet F. Iontophoretic transdermal system using fentanyl compared with patient-controlled intravenous analgesia using morphine for postoperative pain management. Br J Anaesth. 2007;98(6): 806-815.

6. Hartrick CT, Bourne MH, Gargiulo K, Damaraju CV, Vallow S, Hewitt DJ. Fentanyl iontophoretic transdermal system for acute-pain management after orthopedic surgery: a comparative study with morphine intravenous patient-controlled analgesia. Reg Anesth Pain Med. 2006;31(6):546-554.

7. Minkowitz HS, Rathmell JP, Vallow S, Gargiulo K, Damaraju CV, Hewitt DJ. Efficacy and safety of the fentanyl iontophoretic transdermal system (ITS) and intravenous patient-controlled analgesia (IV PCA) with morphine for pain management following abdominal or pelvic surgery. Pain Med. 2007;8(8):657-668.

8. Viscusi ER, Reynolds L, Chung F, Atkinson LE, Khanna S. Patientcontrolled transdermal fentanyl hydrochloride vs intravenous morphine pump for postoperative pain: a randomized controlled trial. JAMA. 2004;291(11):1333-1341.

9. The Medicines Company. IONSYS ${ }^{\circledR}$ (Fentanyl Iontophoretic Transdermal System) US Prescribing Information. Parsippany, NJ: The Medicines Company; 2015.

10. Sathyan G, Jaskowiak J, Evashenk M, Gupta S. Characterisation of the pharmacokinetics of the fentanyl $\mathrm{HCl}$ patient-controlled transdermal system (PCTS): effect of current magnitude and multiple-day dosing and comparison with IV fentanyl administration. Clin Pharmacokinet. 2005;44(suppl 1):7-15.

11. Gupta SK, Bernstein KJ, Noorduin H, Van Peer A, Sathyan G, Haak R. Fentanyl delivery from an electrotransport system: delivery is a function of total current, not duration of current. J Clin Pharmacol. 1998;38(10):951-958.

12. Camu F, Van Aken H, Bovill JG. Postoperative analgesic effects of three demand-dose sizes of fentanyl administered by patient-controlled analgesia. Anesth Analg. 1998;87(4):890-895.

13. Joshi N, Lemke J, Danesi H. Design and functionality of a smart fentanyl iontophoretic transdermal system for the treatment of moderate-tosevere postoperative pain. Pain Manag. In press 2016.

14. Lopez-Munoz F, Alamo C. The consolidation of neuroleptic therapy: Janssen, the discovery of haloperidol and its introduction into clinical practice. Brain Res Bull. 2009;79(2):130-141.

15. Stanley TH. The history and development of the fentanyl series. J Pain Symptom Manage. 1992;7(3 suppl):S3-S7.

16. Trescot AM, Datta S, Lee M, Hansen H. Opioid pharmacology. Pain Physician. 2008;11(2 suppl):S133-S153.

17. Chelly JE, Grass J, Houseman TW, Minkowitz H, Pue A. The safety and efficacy of a fentanyl patient-controlled transdermal system for acute postoperative analgesia: a multicenter, placebo-controlled trial. Anesth Analg. 2004;98(2):427-433. [table of contents].

18. Viscusi ER, Reynolds L, Tait S, Melson T, Atkinson LE. An iontophoretic fentanyl patient-activated analgesic delivery system for postoperative pain: a double-blind, placebo-controlled trial. Anesth Analg. 2006;102(1):188-194.

19. Rothman M, Vallow S, Damaraju CV, Hewitt DJ. Using the patient global assessment of the method of pain control to assess new analgesic modalities in clinical trials. Curr Med Res Opin. 2009;25(6): $1433-1443$. 
20. Sinatra RS, Grond S [webpage on the Internet]. Meta-analysis of the efficacy and safety of the fentanyl iontophoretic transdermal system (ITS) versus intravenous patient-controlled analgesia (IV PCA) in postoperative pain management (\#238). Available from: http://www. painmed.org/2015posters/abstract-238/. Accessed April 15, 2015.

21. Viscusi ER, Grond S, Ding L, Danesi H, Jones JB, Sinatra RS. A comparison of opioid-related adverse events with fentanyl iontophoretic transdermal system versus morphine intravenous patient-controlled analgesia in acute postoperative pain. Pain Manag. 2016;6(1):19-24.

22. Minkowitz H, Joshi N, Phipps B, Wilcox SB, Sneeringer P. Human factors results for IONSYS (fentanyl transdermal system) for postoperative pain management (Abstract S-209). Anesth Analg. 2014;118(S1):S209.

23. Pennington P, Caminiti S, Schein JR, Hewitt DJ, Nelson WW. Patients' assessment of the convenience of fentanyl $\mathrm{HCl}$ iontophoretic transdermal system (ITS) versus morphine intravenous patient-controlled analgesia (IV PCA) in the management of postoperative pain after major surgery. Pain Manag Nurs. 2009;10(3):124-133.

24. Harding G, Schein JR, Nelson WW, et al. Development and validation of a new instrument to evaluate the ease of use of patient-controlled analgesic modalities for postoperative patients. J Med Econ. 2010; 13(1):42-54.
25. Markey DW, Brown RJ. An interdisciplinary approach to addressing patient activity and mobility in the medical-surgical patient. J Nurs Care Qual. 2002;16(4):1-12.

26. Delaney CP, Zutshi M, Senagore AJ, Remzi FH, Hammel J, Fazio VW. Prospective, randomized, controlled trial between a pathway of controlled rehabilitation with early ambulation and diet and traditional postoperative care after laparotomy and intestinal resection. Dis Colon Rectum. 2003;46(7):851-859.

27. Oliasharizi A, Wilson-Byrne T, Shuler FD, Parvizi J. Patient-controlled tentanyl iontophoretic transdermal system (fentanyl ITS) improved postoperative mobility compared to intravenous patient-controlled analgesia (IV PCA) morphine: a pooled analysis of randomized, controlled trials. Pain Pract. 2016 [in press].

28. Bourne MH, Chelly JE, Damaraju CV, Nelson WW, Schein JR, Hewitt DJ. Physical therapists' perceptions of ease of care in patients receiving 2 forms of analgesia after total hip arthroplasty. Phys Ther. 2010;90(5):707-713.
Journal of Pain Research

\section{Publish your work in this journal}

The Journal of Pain Research is an international, peer-reviewed, open access, online journal that welcomes laboratory and clinical findings in the fields of pain research and the prevention and management of pain. Original research, reviews, symposium reports, hypothesis formation and commentaries are all considered for publication.

\section{Dovepress}

The manuscript management system is completely online and includes a very quick and fair peer-review system, which is all easy to use. Visit http://www.dovepress.com/testimonials.php to read real quotes from published authors. 